\section{(6) OPEN ACCESS}

\title{
Time for bed: associations with cognitive performance in 7-year-old children: a longitudinal population-based study
}

\author{
Yvonne Kelly, John Kelly, Amanda Sacker
}

\begin{abstract}
- Additional material is published online only. To view please visit the journal online (http://dx.doi.org/10.1136/jech2012-202024)
\end{abstract}

Department of Epidemiology and Public Health, University College London, London, UK

\section{Correspondence to}

Professor Yvonne Kelly, Department of Epidemiology and Public Health, University College London, 1-19 Torrington Place, London WC1E 6BT, UK,

y.kelly@ucl.ac.uk

Received 4 October 2012 Revised 9 January 2013 Accepted 29 May 2013 Published Online First 8 July 2013

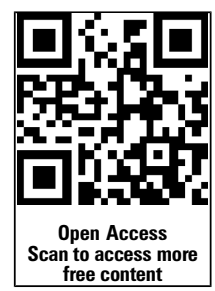

To cite: Kelly Y, Kelly J, Sacker A. J Epidemiol Community Health 2013;67:926-931.

\begin{abstract}
Background Little is known about the links between the time that young children go to bed and their cognitive development. In this paper we seek to examine whether bedtimes in early childhood are related to cognitive test scores in 7-year-olds.

Methods We examined data on bedtimes and cognitive test (z-scores) for reading, maths and spatial abilities for 11178 7-year-old children from the UK Millennium Cohort Study.

Results At age 7, not having a regular bedtime was related to lower cognitive test scores in girls: reading $(\beta:-0.22)$, maths $(\beta:-0.26)$ and spatial ( $\beta:-0.15)$, but not for boys. Non-regular bedtimes at age 3 were independently associated, in girls and boys, with lower reading ( $\beta$ : $-0.10,-0.20)$, maths $(\beta:-0.16,-0.11)$ and spatial ( $\beta$ : $-0.13,-0.16)$ scores. Cumulative relationships were apparent. Girls who never had regular bedtimes at ages 3,5 and 7 had significantly lower reading ( $\beta$ : -0.36$)$, maths ( $\beta$ : -0.51$)$ and spatial ( $\beta$ : -0.40$)$ scores, while for boys this was the case for those having non-regular bedtimes at any two ages ( 3,5 or 7 years): reading ( $\beta$ : $-0.28)$, maths ( $\beta:-0.22)$ and spatial ( $\beta$ : -0.26$)$ scores. In boys having non-regular bedtimes at all three ages $(3,5$ and 7 years) were non-significantly related to lower reading, maths and spatial scores.

Conclusions The consistent nature of bedtimes during early childhood is related to cognitive performance. Given the importance of early child development, there may be knock on effects for health throughout life.
\end{abstract}

\section{INTRODUCTION}

Sleep has a crucial and complex role in the maintenance of health and optimal function, ${ }^{12}$ and is regulated by a combination of social and biological phenomena. Under homeostasis, during wakefulness, environmental stimuli lead to plastic changes in the brain, and associated metabolic activities contribute to a build-up of 'sleep pressure'. ${ }^{3}$ Sleep is the price we pay for plasticity on the prior day and the investment needed to allow learning fresh the next day. ${ }^{4}$ Circadian rhythms are also important and can become disrupted when consistent sleep schedules are not in place. ${ }^{5}$

The amount of sleep needed varies among individuals and across the lifecourse. In 7-year-old children it is estimated that $10-11 \mathrm{~h} / 24 \mathrm{~h}$ period is sufficient. ${ }^{6}$ A range of social and environmental factors, including parental employment, and family routines have been shown to influence the amount and quality of sleep children get. ${ }^{7}$ Therefore, busy family lives could leave parents and carers feeling as though they do not have enough time with their children, and it might be that bedtimes get pushed back or are not routinely in place. This could have important ramifications as when sleep is restricted or disrupted symptoms that reflect a reduced capacity for plastic change and/or disrupted circadian rhythms follow, including cognitive impairment and lack of concentration. ${ }^{9} 10$ Early child development has profound influences on health and well-being across the lifecourse. ${ }^{11}$ Therefore, reduced or disrupted sleep, especially if it occurs at key times in development, could have important impacts on health throughout life.

Most prior work on sleep and cognitive function has been conducted on adults and adolescents, and recent reviews point to the need for population-based studies, set in early childhood ${ }^{12-15}$ that examine markers of sleep in relation to multiple measures of cognitive performance. Few prior studies ${ }^{16-18}$ have considered these associations longitudinally. In this paper, we examine data from a large nationally representative prospective population-based cohort study to see whether and how reported bedtimes through early childhood relate to markers of cognitive performance at 7 years of age.

First, we look cross-sectionally to assess whether the time children go to bed and the consistency of bedtimes are related to cognitive test scores. Second, we look longitudinally to consider whether there are sensitive period or cumulative effects of markers of bedtimes through early childhood.

\section{METHODS}

\section{Millennium Cohort Study}

The Millennium Cohort Study (MCS) is a nationally representative longitudinal study of infants born in the UK. The sample was drawn from births in the UK between September 2000 and January 2002. The survey design, recruitment process and fieldwork have been described in detail elsewhere (http://cls.ioe.ac.uk/shared/get-file. ashx?id=598\& itemtype $=$ document). ${ }^{19}$ The first four sweeps of the survey involved home visits by interviewers when cohort members were aged 9 months, 3, 5 and 7 years. During structured interviews at home visits questions were asked about socioeconomic circumstances, demographic characteristics, family routines including bedtimes and psychosocial environment. At age 7, cognitive assessments were carried out by trained interviewers. Ethical approval for the MCS was gained from the relevant Ethics Committees and parents gave informed consent before interviews took place, and separate written consent for cognitive assessments. 


\section{Bedtimes}

When cohort members were aged 3, 5 and 7 years the mother was asked "On weekdays during term-time, does your child go to bed at a regular time?" (response categories were: always, usually, sometimes and never). A binary variable was created to denote whether a cohort member had a regular bedtime (always/usually vs sometimes/never). Questions were not asked about bedtimes at weekends.

For cohort members with regular bedtimes we created bedtime categories, using responses to the question (asked at ages 5 and 7 years only), "What time is that on a weekday (during term-time)?”

\section{Cognitive assessments}

Three aspects of cognitive performance were assessed: reading, maths and spatial abilities. Reading was tested using the British Ability Scale (BAS) Word Reading assessment, ${ }^{20}$ in which the child reads aloud a series of words presented on a card. Data are presented for the word reading standard score.

Maths skills were assessed using an adapted version of the National Foundation for Educational Research (NFER) Progress in Maths test (MCS edition). Children completed various numberbased tasks, covering the topics of numbers; shape, space and measures and data handling. Data for the total score are presented.

Spatial skills were assessed using the BAS Pattern Construction test, ${ }^{20}$ during which the child constructs a design by putting together flat squares or solid cubes with black and yellow patterns on each side. The child's score is based on accuracy and speed. Data are presented for the T-score, which is standardised based on the child's score relative to the average score of the BAS norming sample for children of the same age group. These assessments use age-related starting points and alternative stopping points to protect the motivation and selfesteem of the child. ${ }^{21}$ Interviewers were trained to minimise the impact of extraneous factors that might impact on the child's performance, including excessive noise and interruptions, and building a supportive rapport with the child. To aid model comparability we present $\mathrm{z}$-score values in our multivariate models.

\section{Study sample}

We use data for singleton born cohort members whose mothers were the main interview respondent and for whom information was collected on bedtimes at ages 3, 5 and 7 years $(n=11178)$. Missing data on variables included in multivariate models reduced the sample size available for our three markers of cognitive performance: for reading to 10242 (91.6\%), for maths to $10384(92.9 \%)$ and for spatial abilities to $10357(92.7 \%)$.

\section{Analytical approach}

We hypothesised that a range of factors could confound the association between bedtimes and markers of cognitive test performance, while other factors would more directly influence the quantity, and the quality of sleep children get. This conceptualisation informed our analytical approach: model A adjusts for the age of the child; model B additionally adjusts for confounding factors and in model $\mathrm{C}$ we additionally adjust for factors that likely influence sleep quantity and quality. Confounding factors (model B) were: interview season (winter, spring, summer, autumn), school year, mother's age in years, birth order (first or later born), languages spoken in the home (English only, English plus other, other language), family income ( $£ 52000$ or more, $£ 31200-£ 51999$, $£ 20$ 800-£31,199, £10 400-£20 799, less than $£ 10400$, not known), highest parental qualification (higher degree, first degree/ diploma, Advanced/Advanced Supplementary (A/AS) levels, General Certificate of Secondary Education (GCSE) grades A-C, GCSE grades D-G, other/overseas, none), mother's psychological distress (assessed using the Kessler six-item questionnaire, K6), ${ }^{22}$ discipline strategies-a composite score of seven items, $\alpha=0.65$ (How often (never, rarely, sometimes about once per month, often about once or more per week, daily) do you do the following when child is 'naughty': ignore, smack, shout, send to bedroom/ naughty chair, take away treats, tell off, bribe), mother often irritated with child, mother's self-rated parenting competence (better than average vs average or below average), whether breastfed, whether smoked in pregnancy, whether drank alcohol in pregnancy, skips breakfast, daily activities-musical, drawing and/or painting, help with reading, hours spent watching TV (less than $1 \mathrm{~h}, 1 \mathrm{~h}$ to under $3 \mathrm{~h}, 3 \mathrm{~h}$ or more), hours spent using computer (less than $1 \mathrm{~h}, 1 \mathrm{~h}$ to under $3 \mathrm{~h}, 3 \mathrm{~h}$ or more). In presented models we retained confounding variables that, in multivariate analysis, were statistically related both to reported bedtimes and to cognitive test scores at the $10 \%(\mathrm{p}<0.10)$ level.

In model $\mathrm{C}$ we attempted to take account of factors that could truncate the amount of time children spend in bed and possibly the regularity of bedtimes, and potential disruptions to sleep. Factors we conceptualised as potentially affecting the amount of time children spent in bed and/or the regularity of bedtimes were: parental employment (two parent-both employed, mother only, father only, neither employed; one parent-employed, not employed), whether parents felt they had enough time with child (more than enough, just enough, not quite enough, nowhere near enough), child attends breakfast or after school club, any other childcare used, reading and telling stories to child daily, having rules about time spent watching TV, factors that might disrupt sleep, thereby influencing sleep quality were: overcrowding ( $>1$ person/room), child wets bed, having a TV in bedroom. We retained variables added to model $\mathrm{C}$ that, in multivariate analysis, were statistically related to cognitive test scores at the $10 \%(\mathrm{p}<0.10)$ level.

\section{Data analysis}

Data were analysed using Stata V.11.2 (Stata Corporation, 2009). Analyses were weighted to take account of the stratified and clustered sample design and the unequal probability of being sampled. Associations between reported bedtimes and bedtime regularity and markers of cognitive performance were conducted using multivariate linear regression models.

\section{RESULTS}

Not having a regular bedtime was most common at age 3 (19.5\%) compared with ages 5 and 7 , respectively $(9.1 \%$ and $8.2 \%)$. At age 7 reported bedtimes were distributed as follows: before 7:30 (10.5\%), 7:30-7:59 (24.2\%), 8:00-8:29 (34.1\%), 8:30-8:59 (13.9\%), 9:00-9:29 (7.8\%), 9:30 or later (1.3\%).

Children without regular bedtimes and those with later bedtimes (after 9:00) had more socially disadvantaged profiles (see online supplementary appendix table A1). For example, they were more likely to be from the poorest homes, have parents without degree level qualifications and mothers with poorer mental health. Patterns of parental employment and whether parents felt that they had enough time with their children did not vary much across bedtime categories. Children with late and non-regular bedtimes were more likely to have unfavourable routines, for example, skipping breakfast, to not be read to daily, to have a TV in their bedroom and to have longer periods (>3 h/day) TV viewing compared with children with earlier bedtimes. Compared with families who were lost to follow-up 
or did not participate in all four MCS sweeps, the study sample was more socially advantaged-parents had higher incomes, better educational qualifications and were more likely to be employed in professional and managerial occupations (see online supplementary appendix table A2).

In cross-sectional analyses, crude results (table 1, model A) suggested that for girls not having a regular bedtime, or having an early (before 19:30) or late (after 21:00) bedtime tended to be associated with lower cognitive test scores. These differences were somewhat attenuated on statistical adjustment for confounding factors (table 1, model B), but in fully adjusted models not having a regular bedtime remained statistically significant for reading $(\beta:-0.22)$, maths $(\beta:-0.26)$ and spatial $(\beta:-0.15)$ scores (table 1 , model $\mathrm{C}$ ). For boys crude differences in reading, maths and spatial scores disappeared entirely on adjustment for confounding factors.

Next we looked longitudinally, to see whether we detected sensitive period, and/or cumulative associations between non-regular bedtimes throughout early childhood and cognitive performance at age 7 . In the first step of this analysis we simultaneously coadjusted for non-regular bedtime at ages 3,5 and 7. Model results suggested that non-regular bedtimes at age 3 were independently associated, in girls and boys, with lower reading ( $\beta$ : $-0.10,-0.20)$, maths $(\beta:-0.16,-0.11)$ and spatial $(\beta:-0.13,-0.16)$ scores (table 2 , model $\mathrm{C}$ ). The overall picture suggested that non-regular bedtimes at age 5 were not independently associated with cognitive test scores at age 7 , except for reading scores $(\beta:-0.15)$ in girls and maths scores $(\beta:-0.14)$ in boys.

In the next step, we looked to see whether cumulative relationships were apparent. The results suggested that girls who never had regular bedtimes at ages 3,5 and 7 had significantly lower reading $(\beta:-0.36)$, maths $(\beta:-0.51)$ and spatial $(\beta:-0.40)$ scores, while for boys this was the case for those having non-regular bedtimes at any two ages $(3,5$ or 7 years); reading ( $\beta$ : -0.28$)$, maths $(\beta:-0.22)$ and spatial $(\beta:-0.26)$ scores (table 3 , model $C)$. Boys who had non-regular bedtimes at all three ages (3, 5 and 7 years) also had lower cognitive test scores, but these differences were not statistically significant. Sensitivity analyses confirmed that the findings were not restricted to children born preterm.

\section{DISCUSSION}

\section{Main findings}

Our cross-sectional findings suggest that non-regular and late bedtimes in 7-year-olds have small but statistically significant associations with lower reading, maths and spatial skill scores for girls, but not for boys. Our longitudinal analysis suggests that there may be sensitive period effects, whereby not having regular bedtimes at age 3 is independently associated with markers of cognitive performance at age 7 for girls and boys, but the size of these associations is relatively modest-one-sixth to one-fifth of a SD difference in test scores. Our results also suggest that cumulative pathways may be at play, such that nonregular bedtimes throughout early childhood are related to lower cognitive test scores at age 7 . The size of these relationships were relatively large in girls, with between a third and a half of an SD difference in test scores. Among boys with nonregular bedtimes at any two ages there was about a quarter of a SD difference in test scores.

\section{Interpretation}

Inconsistent bedtime schedules might impact on markers of cognitive development in two ways, via (1) disruptions to circadian rhythms and/or (2) sleep deprivation and associated effects on brain plasticity. Consistent schedules are linked to better entrained circadian rhythms and these are slow to adapt. ${ }^{5}$ Sleep is crucial for the maintenance of homeostasis and brain plasticity, including processes to do with embedding new knowledge, memory and skills into developing neural assemblies. ${ }^{14}$ Given the interactive nature of circadian and homeostatic processes that govern sleep, ${ }^{3}{ }^{4}$ inconsistent schedules are likely to have knock on effects for daytime functioning. A recent review ${ }^{15}$ concluded that inconsistent sleep and wake schedules, short sleep, late bed and rise times and poor sleep quality are all linked to markers of academic performance, but not all studies have findings consistent with this view. ${ }^{23} 24$ We find that inconsistent bedtimes appear to matter for markers of cognitive performance in early childhood. Inconsistent bedtimes do not necessarily equate to short sleep duration though studies do suggest links between these parameters of sleep.

Our longitudinal findings are consistent with the few small-scale studies that looked prospectively at parameters of sleep in relation to aspects of cognitive performance, although most prior work has been cross-sectional and/or carried out on small study samples. A study by Touchette $e t a l^{16}$ suggested that short sleep duration at 2.5 years of age, even if followed by sufficient amounts of sleep up to the age of 6 was associated with poor cognitive test performance compared with children who had sufficient sleep throughout early childhood. Recently, Buckhalt et $a l^{17}$ showed that nonclinical level sleep problems, including inconsistent sleep schedules, detracted from later cognitive performance among 8 -year-old children who were followed for 2 years. Another study from the same research group reported prospectively that for girls daytime sleepiness was linked to test scores 2 years later. ${ }^{18}$ Results from observational studies are supported by findings from experimental investigations which have demonstrated impaired cognitive functioning following periods of sleep restriction and alterations in sleep schedules. 91013

Our longitudinal observations suggest that there may be sensitive period and cumulative mechanisms at play between inconsistent bedtime schedules and cognitive test scores. This is not surprising as the acquisition of knowledge and skills is a central developmental process in early childhood and later gains are built on what has previously been learnt. This might be particularly problematic when disruptions to sleep occur at key points in early development. Thus, bedtime schedules in the first few years of life might set children onto particular trajectories in relation to their cognitive development.

We anticipated that time pressures associated with parental employment and family activities would influence bedtimes, and the consistent enforcement of bedtimes. We found that rates of parental employment and whether parents felt they spent enough time with their child did not vary substantially by markers of bedtime. However, in keeping with prior studies, 7825 other markers of the family milieu that we know are important predictors of early child development, ${ }^{26}$ including mother's mental health and daily routines (eg, skipping breakfast, reading to/with child, having a TV in the bedroom and the amount of TV watched) were all strongly correlated with inconsistent bedtime schedules and later bedtimes.

It might be that inconsistent bedtimes are a reflection of chaotic family settings and it is this, rather than disrupted sleep that impacts on cognitive performance in children. However, we found that inconsistent bedtimes were linked to markers of cognitive performance independent of multiple markers of stressful family environments. Findings from elsewhere suggest that stressful family environments affect children's functioning via effects on sleep. ${ }^{25} 27$ Thus our results suggest that having a regular bedtime is important alongside other aspects of family 
Table 1 Regression coefficients (95\% Cls) for cognitive test scores by bedtimes at age 7, cross-sectional analysis

\begin{tabular}{|c|c|c|c|c|c|c|c|c|}
\hline Bedtime & $\mathrm{n}$ & Mean & Model A & & Model B & & Model C & \\
\hline Girls & & & & & & & & \\
\hline Reading & & & & & & & & \\
\hline Before 19:30 & 488 & 112.4 & -0.17 & $(-0.27$ to -0.07$)$ & -0.09 & $(-0.18$ to 0.00$)$ & -0.09 & $(-0.18$ to 0.00$)$ \\
\hline 19:30-19:59 & 1083 & 116.0 & 0.03 & $(-0.05$ to 0.11$)$ & 0.01 & $(-0.06$ to 0.08$)$ & 0.00 & ( -0.07 to 0.07$)$ \\
\hline 20:00-20:29 (ref) & 1713 & 115.3 & - & & - & & - & \\
\hline $20: 30-20: 59$ & 814 & 113.1 & -0.12 & $(-0.21$ to -0.03$)$ & -0.07 & $(-0.15$ to 0.01$)$ & -0.06 & $(-0.14$ to 0.02$)$ \\
\hline 21:00-21:29 & 466 & 110.8 & -0.25 & $(-0.34$ to -0.15$)$ & -0.13 & $(-0.23$ to -0.04$)$ & -0.11 & $(-0.20$ to -0.01$)$ \\
\hline $21: 30$ or later & 85 & 107.6 & -0.42 & $(-0.68$ to -0.16$)$ & -0.34 & $(-0.63$ to -0.06$)$ & -0.33 & $(-0.62$ to -0.05$)$ \\
\hline Not regular & 434 & 108.6 & -0.38 & $(-0.49$ to -0.26$)$ & -0.24 & $(-0.34$ to -0.14$)$ & -0.22 & $(-0.32$ to -0.12$)$ \\
\hline Maths & & & & & & & & \\
\hline Before $19: 30$ & 495 & 9.4 & -0.18 & $(-0.29$ to -0.08$)$ & -0.14 & $(-0.23$ to -0.04$)$ & -0.14 & $(-0.23$ to -0.05$)$ \\
\hline 19:30-19:59 & 1105 & 9.8 & -0.03 & $(-0.11$ to 0.05$)$ & -0.05 & $(-0.12$ to 0.02$)$ & -0.06 & $(-0.13$ to 0.01$)$ \\
\hline 20:00-20:29 (ref) & 1738 & 9.9 & - & & - & & - & \\
\hline 20:30-20:59 & 819 & 9.6 & -0.12 & $(-0.21$ to -0.04$)$ & -0.08 & $(-0.15$ to 0.00$)$ & -0.07 & $(-0.14$ to 0.01$)$ \\
\hline $21: 00-21: 29$ & 475 & 9.5 & -0.16 & $(-0.27$ to -0.04$)$ & 0.00 & $(-0.11$ to 0.11$)$ & 0.01 & $(-0.10$ to 0.11$)$ \\
\hline $21: 30$ or later & 85 & 9.6 & -0.12 & $(-0.33$ to 0.09$)$ & 0.04 & $(-0.19$ to 0.27$)$ & 0.05 & $(-0.17$ to 0.28$)$ \\
\hline Not regular & 440 & 8.8 & -0.39 & $(-0.53$ to -0.26$)$ & -0.26 & $(-0.39$ to -0.14$)$ & -0.26 & $(-0.38$ to -0.14$)$ \\
\hline Spatial & & & & & & & & \\
\hline Before 19:30 & 491 & 52.9 & -0.14 & $(-0.24$ to -0.04$)$ & -0.08 & $(-0.18$ to 0.02$)$ & -0.08 & $(-0.17$ to 0.02$)$ \\
\hline 19:30-19:59 & 1,106 & 54.0 & -0.04 & $(-0.12$ to 0.05$)$ & -0.05 & $(-0.12$ to 0.03$)$ & -0.05 & $(-0.13$ to 0.03$)$ \\
\hline 20:00-20:29 (ref) & 1,734 & 54.4 & - & & - & & - & \\
\hline $20: 30-20: 59$ & 814 & 54.1 & -0.03 & $(-0.12$ to 0.06$)$ & 0.01 & ( -0.09 to 0.08$)$ & 0.00 & $(-0.09$ to 0.08$)$ \\
\hline $21: 00-21: 29$ & 474 & 53.1 & -0.12 & $(-0.23$ to -0.01$)$ & 0.01 & $(-0.10$ to 0.12$)$ & 0.01 & $(-0.09$ to 0.12$)$ \\
\hline $21: 30$ or later & 85 & 52.2 & -0.20 & $(-0.42$ to 0.01$)$ & -0.10 & $(-0.33$ to 0.14$)$ & -0.07 & $(-0.31$ to 0.17$)$ \\
\hline Not regular & 440 & 51.3 & -0.28 & $(-0.42$ to -0.14$)$ & -0.15 & $(-0.28$ to -0.02$)$ & -0.15 & $(-0.28$ to -0.03$)$ \\
\hline Boys & & & & & & & & \\
\hline Reading & & & & & & & & \\
\hline Before 19:30 & 411 & 110.1 & -0.09 & $(-0.22$ to 0.03$)$ & 0.00 & $(-0.12$ to 0.11$)$ & 0.01 & $(-0.10$ to 0.12$)$ \\
\hline 19:30-19:59 & 1,079 & 112.2 & 0.02 & $(-0.06$ to 0.11$)$ & 0.01 & $(-0.07$ to 0.09$)$ & 0.00 & $(-0.07$ to 0.08$)$ \\
\hline $20: 00-20 ; 29$ (ref) & 1,791 & 111.7 & - & & - & & - & \\
\hline $20: 30-20: 59$ & 840 & 111.9 & 0.02 & $(-0.09$ to 0.13$)$ & 0.03 & $(-0.08$ to 0.13$)$ & 0.03 & $(-0.07$ to 0.14$)$ \\
\hline 21:00-21:29 & 514 & 109.3 & -0.13 & $(-0.25$ to -0.02$)$ & 0.00 & $(-0.12$ to 0.11$)$ & 0.02 & $(-0.10$ to 0.13$)$ \\
\hline $21: 30$ or later & 76 & 111.1 & -0.03 & $(-0.29$ to 0.22$)$ & 0.08 & $(-0.14$ to 0.31$)$ & 0.14 & $(-0.09$ to 0.37$)$ \\
\hline Not regular & 448 & 107.8 & -0.21 & $(-0.35$ to -0.07$)$ & -0.09 & $(-0.23$ to 0.05$)$ & -0.05 & $(-0.19$ to 0.09$)$ \\
\hline Maths & & & & & & & & \\
\hline Before $19: 30$ & 418 & 9.6 & -0.10 & $(-0.21$ to 0.01$)$ & -0.03 & $(-0.14$ to 0.09$)$ & -0.01 & $(-0.12$ to 0.10$)$ \\
\hline 19:30-19:59 & 1,097 & 9.8 & -0.01 & $(-0.09$ to 0.07$)$ & -0.03 & $(-0.10$ to 0.05$)$ & -0.03 & $(-0.11$ to 0.05$)$ \\
\hline $20: 00-20: 29$ (ref) & 1,808 & 9.9 & - & & - & & - & \\
\hline $20: 30-20: 59$ & 853 & 10.0 & 0.03 & $(-0.06$ to 0.13$)$ & 0.05 & $(-0.05$ to 0.14$)$ & 0.05 & $(-0.04$ to 0.14$)$ \\
\hline $21: 00-21: 29$ & 518 & 9.5 & -0.15 & $(-0.27$ to -0.03$)$ & -0.02 & $(-0.13$ to 0.10$)$ & 0.00 & $(-0.12$ to 0.12$)$ \\
\hline $21: 30$ or later & 77 & 9.2 & -0.25 & ( -0.57 to 0.08$)$ & -0.10 & $(-0.43$ to 0.24$)$ & -0.07 & $(-0.41$ to 0.27$)$ \\
\hline Not regular & 456 & 9.6 & -0.12 & $(-0.27$ to 0.02$)$ & 0.01 & $(-0.13$ to 0.16$)$ & 0.04 & $(-0.11$ to 0.18$)$ \\
\hline Spatial & & & & & & & & \\
\hline Before 19:30 & 418 & 52.5 & -0.12 & $(-0.24$ to -0.01$)$ & -0.06 & $(-0.17$ to 0.06$)$ & -0.04 & $(-0.15$ to 0.07$)$ \\
\hline 19:30-19:59 & 1,098 & 54.2 & 0.03 & $(-0.05$ to 0.12$)$ & 0.02 & $(-0.06$ to 0.10$)$ & 0.01 & $(-0.07$ to 0.09$)$ \\
\hline $20: 00-20: 29$ (ref) & 1,801 & 53.9 & - & & - & & - & \\
\hline 20:30-20:59 & 850 & 53.5 & -0.03 & $(-0.13$ to 0.06$)$ & -0.01 & $(-0.11$ to 0.08$)$ & -0.01 & $(-0.10$ to 0.09$)$ \\
\hline $21: 00-21: 29$ & 519 & 50.7 & -0.29 & $(-0.40$ to -0.17$)$ & -0.16 & $(-0.27$ to -0.06$)$ & -0.14 & $(-0.25$ to -0.04$)$ \\
\hline $21: 30$ or later & 75 & 52.8 & -0.10 & $(-0.34$ to 0.14$)$ & 0.07 & $(-0.17$ to 0.31$)$ & 0.09 & $(-0.15$ to 0.32$)$ \\
\hline Not regular & 452 & 51.6 & -0.20 & $(-0.33$ to -0.07$)$ & -0.07 & $(-0.19$ to 0.06$)$ & -0.04 & $(-0.17$ to 0.09$)$ \\
\hline
\end{tabular}

Model $\mathrm{A}$ adjusts for child's age.

Model B additionally adjusts for interview season, school year, mother's age in years, birth order, languages spoken in the home, family income, highest parental qualification, mother's psychological distress, discipline strategies, mother often irritated with child, mother's parenting competence, breastfed, skips breakfast, musical activities at home, drawing/painting activities at home, helped with reading, TV hours per weekday, computer hours per weekday.

Model C additionally adjusts for parental employment, mother's view of amount of time with child, father's view of amount of time with child, child attends breakfast club, child attends after school club, any other childcare, child read to, child told stories, TV time rules, overcrowding, child wets bed, TV in bedroom.

circumstances. We found that statistical adjustment for confounding factors did most to attenuate associations between markers of bedtimes and cognitive test scores. Our findings suggest more marked associations among girls. It might be that girls are more susceptible to elements of the psychosocial environment than boys and hence also more easily perturbed by inconsistent bedtime schedules. ${ }^{18} 2829$ We also observed lower cognitive test scores for girls with early bedtimes and this might 
Table 2 Regression coefficients (95\% Cls) for cognitive test scores at age 7, by non-regular bedtimes throughout early childhood, 'sensitive period' analysis

\begin{tabular}{|c|c|c|c|c|c|c|c|c|}
\hline \multirow[b]{2}{*}{ Non-regularbedtime } & \multicolumn{4}{|l|}{ Girls } & \multicolumn{4}{|l|}{ Boys } \\
\hline & \multicolumn{2}{|l|}{ Model A } & \multicolumn{2}{|c|}{ Model C } & \multicolumn{2}{|l|}{ Model A } & \multicolumn{2}{|l|}{ Model C } \\
\hline \multicolumn{9}{|l|}{ Reading } \\
\hline Age 3 & -0.27 & $(-0.34$ to -0.20$)$ & -0.10 & $(-0.18$ to -0.03$)$ & -0.32 & $(-0.42$ to -0.23$)$ & -0.20 & $(-0.30$ to -0.11$)$ \\
\hline Age 5 & -0.26 & $(-0.38$ to -0.15$)$ & -0.15 & ( -0.26 to -0.04$)$ & -0.18 & $(-0.30$ to -0.06$)$ & -0.08 & $(-0.19$ to 0.04$)$ \\
\hline Age 7 & -0.16 & $(-0.28$ to -0.05$)$ & -0.12 & $(-0.22$ to -0.02$)$ & -0.06 & $(-0.19$ to 0.07$)$ & 0.00 & $(-0.13$ to 0.12$)$ \\
\hline \multicolumn{9}{|l|}{ Maths } \\
\hline Age 3 & -0.29 & $(-0.37$ to -0.21$)$ & -0.16 & $(-0.24$ to -0.08$)$ & -0.23 & $(-0.33$ to -0.13$)$ & -0.11 & $(-0.21$ to -0.02$)$ \\
\hline Age 5 & -0.14 & $(-0.25$ to -0.02$)$ & -0.06 & ( -0.17 to 0.06$)$ & -0.25 & $(-0.37$ to -0.14$)$ & -0.14 & $(-0.26$ to -0.03$)$ \\
\hline Age 7 & -0.21 & $(-0.33$ to -0.08$)$ & -0.17 & $(-0.29$ to -0.06$)$ & 0.04 & $(-0.10$ to 0.18$)$ & 0.09 & $(-0.04$ to 0.23$)$ \\
\hline \multicolumn{9}{|l|}{ Spatial } \\
\hline Age 3 & -0.26 & $(-0.34$ to -0.18$)$ & -0.13 & $(-0.21$ to -0.06$)$ & -0.28 & $(-0.36$ to -0.19$)$ & -0.16 & $(-0.24$ to -0.08$)$ \\
\hline Age 5 & -0.17 & $(-0.28$ to -0.05$)$ & -0.07 & $(-0.18$ to 0.04$)$ & -0.19 & $(-0.31$ to -0.07$)$ & -0.11 & $(-0.23$ to 0.00$)$ \\
\hline Age 7 & -0.11 & $(-0.25$ to 0.02$)$ & -0.09 & $(-0.21$ to 0.03$)$ & -0.03 & $(-0.16$ to 0.09$)$ & 0.04 & $(-0.08$ to 0.16$)$ \\
\hline
\end{tabular}

Model A adjusts for child's age.

Model C additionally adjusts for interview season, school year, mother's age in years, birth order, languages spoken in the home, family income, highest parental qualification, mother's psychological distress, discipline strategies, mother often irritated with child, mother's parenting competence, breastfed, skips breakfast, musical activities at home, drawing/painting activities at home, helped with reading. TV hours per weekday, computer hours per weekday, parental employment, mother's view of amount of time with child, father's view of amount of time with child, child attends breakfast club, child attends after school club, any other childcare, child read to, child told stories, TV time rules, overcrowding, child wets bed, TV in bedroom.

reflect more restrictive family settings with limited opportunities for interactions that foster early child development.

\section{Strengths and limitations}

Using data from a large nationally representative prospective population-based study we assessed relationships between markers of bedtimes and multiple measures of cognitive performance, while taking account of a variety of family and home-oriented factors. Survey attrition is a common feature of longitudinal studies, but for this analysis missing data were apparent for less than $10 \%$ of the sample, thus our results can be generalised to the population. Data on bedtimes were from parent report and therefore prone to recall problems which may be influenced by particular experiences and expectations. However, prior studies have shown reasonable

Table 3 Regression coefficients (95\% Cls) for cognitive test scores at age 7, by non-regular bedtimes throughout early childhood, cumulative effects analysis

\begin{tabular}{|c|c|c|c|c|c|c|c|c|}
\hline & \multicolumn{4}{|l|}{ Girls } & \multicolumn{4}{|l|}{ Boys } \\
\hline & \multicolumn{2}{|c|}{ Model A } & \multicolumn{2}{|c|}{ Model C } & \multicolumn{2}{|c|}{ Model A } & \multicolumn{2}{|c|}{ Model C } \\
\hline \multicolumn{9}{|l|}{ Reading } \\
\hline Always regular (ref) & - & & - & & - & & - & \\
\hline Not regular, age 3 only & -0.26 & $(-0.34$ to -0.18$)$ & -0.07 & $(-0.15$ to 0.02$)$ & -0.34 & $(-0.45$ to -0.23$)$ & -0.20 & $(-0.30$ to -0.10$)$ \\
\hline Not regular, age 5 only & -0.29 & $(-0.46$ to -0.12$)$ & -0.15 & $(-0.31$ to 0.01$)$ & -0.29 & $(-0.47$ to -0.10$)$ & -0.08 & $(-0.27$ to 0.11$)$ \\
\hline Not regular, age 7 only & -0.12 & $(-0.28$ to 0.05$)$ & -0.06 & $(-0.21$ to 0.08$)$ & -0.13 & $(-0.32$ to 0.05$)$ & -0.02 & $(-0.20$ to 0.16$)$ \\
\hline Not regular, any 2 ages & -0.52 & $(-0.64$ to -0.40$)$ & -0.30 & $(-0.41$ to -0.18$)$ & -0.49 & $(-0.64$ to -0.34$)$ & -0.28 & $(-0.43$ to -0.13$)$ \\
\hline Never regular & -0.66 & $(-0.90$ to -0.42$)$ & -0.36 & $(-0.58$ to -0.15$)$ & -0.34 & $(-0.64$ to -0.04$)$ & -0.19 & $(-0.44$ to 0.06$)$ \\
\hline \multicolumn{9}{|l|}{ Maths } \\
\hline Always regular (ref) & - & & - & & - & & - & \\
\hline Not regular, age 3 only & -0.29 & $(-0.39$ to -0.20$)$ & -0.14 & $(-0.23$ to -0.05$)$ & -0.21 & $(-0.32$ to -0.11$)$ & -0.08 & $(-0.18$ to 0.02$)$ \\
\hline Not regular, age 5 only & -0.22 & $(-0.39$ to -0.05$)$ & -0.11 & ( -0.27 to 0.06$)$ & -0.26 & $(-0.44$ to -0.08$)$ & -0.05 & $(-0.24$ to 0.13$)$ \\
\hline Not regular, age 7 only & -0.14 & $(-0.33$ to 0.04$)$ & -0.09 & $(-0.26$ to 0.08$)$ & -0.03 & $(-0.24$ to 0.19$)$ & 0.07 & $(-0.13$ to 0.28$)$ \\
\hline Not regular, any 2 ages & -0.37 & $(-0.53$ to -0.21$)$ & -0.21 & $(-0.36$ to -0.06$)$ & -0.44 & $(-0.59$ to -0.29$)$ & -0.22 & $(-0.37$ to -0.07$)$ \\
\hline Never regular & -0.73 & $(-0.99$ to -0.48$)$ & -0.51 & $(-0.75$ to -0.27$)$ & -0.27 & $(-0.52$ to -0.03$)$ & -0.11 & $(-0.32$ to 0.10$)$ \\
\hline \multicolumn{9}{|l|}{ Spatial } \\
\hline Always regular (ref) & - & & - & & - & & - & \\
\hline Not regular, age 3 only & -0.28 & $(-0.38$ to -0.18$)$ & -0.14 & $(-0.23$ to -0.04$)$ & -0.28 & $(-0.38$ to -0.19$)$ & -0.15 & $(-0.24$ to -0.06$)$ \\
\hline Not regular, age 5 only & -0.28 & $(-0.46$ to -0.10$)$ & -0.14 & $(-0.31$ to 0.03$)$ & -0.26 & $(-0.45$ to -0.07$)$ & -0.09 & $(-0.27$ to 0.10$)$ \\
\hline Not regular, age 7 only & -0.21 & $(-0.46$ to 0.03$)$ & -0.18 & $(-0.39$ to 0.04$)$ & -0.16 & $(-0.36$ to 0.04$)$ & -0.04 & $(-0.23$ to 0.14$)$ \\
\hline Not regular, any 2 ages & -0.29 & $(-0.42$ to -0.16$)$ & -0.11 & $(-0.23$ to 0.01$)$ & -0.46 & $(-0.64$ to -0.29$)$ & -0.26 & $(-0.42$ to -0.11$)$ \\
\hline Never regular & -0.61 & $(-0.81$ to -0.41$)$ & -0.40 & $(-0.58$ to -0.22$)$ & -0.26 & $(-0.47$ to -0.05$)$ & -0.10 & $(-0.31$ to 0.11$)$ \\
\hline
\end{tabular}

Model $\mathrm{A}$ adjusts for child's age.

Model C additionally adjusts for interview season, school year, mother's age in years, birth order, languages spoken in the home, family income, highest parental qualification, mother's psychological distress, discipline strategies, mother often irritated with child, mother's parenting competence, breastfed, skips breakfast, musical activities at home, drawing/painting activities at home, helped with reading, TV hours per weekday, computer hours per weekday, parental employment, mother's view of amount of time with child, father's view of amount of time with child, child attends breakfast club, child attends after school club, any other childcare, child read to, child told stories, TV time rules, overcrowding, child wets bed, TV in bedroom. 
agreement between reported bedtimes and estimated sleep time using actigraphy. ${ }^{8}{ }^{30}$ Data on bedtimes at weekends were not available, and therefore it was not possible to build up a picture of bedtime variations across the week. Cross-sectional analysis suggested that late bedtimes were important for girls, but due to small cell sizes and adjustment for multiple covariates, we could not reliably estimate the possible effects of insufficient 'sleep'. Data reporting the times that children go to bed were only available at ages 5 and 7 , so it was not possible to estimate effects throughout early childhood. Another limitation was that direct data on sleep quantity and quality were not available.

\section{CONCLUSIONS}

We show that a range of social and family environmental factors are related to bedtimes during early childhood. Our findings suggest that inconsistent bedtimes, especially at very young ages and/or throughout early childhood, are linked to children's cognitive development. Relations between inconsistent bedtimes and aspects of early child development may have knock on effects for health and broader social outcomes throughout the lifecourse. Families are prone to demands on time that might adversely impact on routines important for healthy development in young children. In light of this, policy development is needed to better support families to provide conditions in which young children can flourish.

\section{What is already known on this subject}

- Sleep is important for the maintenance of healthy functioning.

- Most of the evidence is based on studies in adults and adolescents.

- Prior small-scale studies have produced inconsistent results, and large-scale population-based studies are needed.

\section{What this study adds}

- Consistent bedtimes are independently associated with cognitive test scores at age 7 . Sensitive period-not having a regular bedtime at age 3 , and cumulative effects-not having regular bedtimes throughout early childhood were linked to lower scores.

Acknowledgements We would like to thank the Millennium Cohort Study families for their time and cooperation, as well as the Millennium Cohort Study team at the Institute of Education. The Millennium Cohort Study is funded by ESRC grants to Professor Heather Joshi (study director).

Contributors YK designed the study, and drafted the manuscript. JK provided input on analytical strategy, analysed the data and commented on drafts of the manuscript. AS provided analytical support and commented on drafts of the paper. YK will act as guarantor for the manuscript.

Funding This work was supported by a grant from the Economic and Social Research Council RES-596-28-0001. The funders had no role in the interpretation of these data or in the writing of this paper.

\section{Competing interests None.}

Ethics approval Ethical approval for the MCS was gained from the relevant Ethics Committees and parents gave informed consent before interviews took place, and separate written consent for cognitive assessments.

Provenance and peer review Not commissioned; externally peer reviewed. Data sharing statement Data available from the authors on request.
Open Access This is an Open Access article distributed in accordance with the Creative Commons Attribution Non Commercial (CC BY-NC 3.0) license, which permits others to distribute, remix, adapt, build upon this work non-commercially, and license their derivative works on different terms, provided the original work is properly cited and the use is non-commercial. See: http://creativecommons.org/ licenses/by-nc/3.0/

\section{REFERENCES}

1 Walker MP, Stickgold R. Sleep, memory, and plasticity. Annu Rev Psychol 2006:57:139-66.

2 Bryant PA, Trinder J, Curtis N. Sick and tired: does sleep have a vital role in the immune system? Nat Rev Immunol 2004;4:457-67.

3 Borbély AA, Achermann P. Sleep homeostasis and models of sleep regulation. J Biol Rhythms 1999;14:559-70.

4 Tononi G, Cirelli C. Sleep function and synaptic homeostasis. Sleep Med Rev 2006;10:49-62.

5 Wittmann M, Dinich J, Merrow $M$, et al. Social jetlag: misalignment of biological and social time. Chronobiol Int 2006;23:497-509.

6 Iglowstein I, Jenni OG, Molinari L, et al. Sleep duration from infancy to adolescence: reference values and generational trends. Pediatrics 2003;111:302-7.

7 Mindell JA, Meltzer LJ, Carskadon MA, et al. Developmental aspects of sleep hygiene: findings from the 2004 National Sleep Foundation Sleep in America Poll. Sleep Med 2009;10:771-9.

8 Adam EK, Snell EK, Pendry P. Sleep timing and quantity in ecological and family context: a nationally representative time-diary study. J Fam Psychol 2007:21:4-19.

9 Fallone G, Acebo C, Seifer R, et al. Experimental restriction of sleep opportunity in children: effects on teacher ratings. Sleep 2005:28:1561-7.

10 Sadeh A, Gruber R, Raviv A. The effects of sleep restriction and extension on school-age children: what a difference an hour makes. Child Dev 2003;74:444-55.

11 Commission on Social Determinants of Health (CSDH). Closing the gap in a generation: health equity through action on the social determinants of health Geneva: World Health Organization, 2008.

12 Curcio G, Ferrara M, De Gennaro L. Sleep loss, learning capacity and academic performance. Sleep Med Rev 2006;10:323-37.

13 Sadeh A. Consequences of sleep loss or sleep disruption in children. Sleep Med Clin 2007;2:513-20.

14 Dewald JF, Meijer AM, Oort FJ, et al. The influence of sleep quality, sleep duration and sleepiness on school performance in children and adolescents: a meta-analytic review. Sleep Med Rev 2010;14:179-89.

15 Buckhalt JA. Insufficient sleep and the socioeconomic status achievement gap. Child Dev Perspect 2011;5:59-65.

16 Touchette E, Petit D, Seguin JR, et al. Associations between sleep duration patterns and behavioral/cognitive functioning at school entry. Sleep 2007;30:1213-19.

17 Buckhalt JA, El-Sheikh M, Keller PS, et al. Concurrent and longitudinal relations between children's sleep and cognitive functioning: the moderating role of parent education. Child Dev 2009;80:875-92.

18 Bub KL, Buckhalt JA, El-Sheikh M. Children's sleep and cognitive performance: a cross-domain analysis of change over time. Dev Psychol 2011;47:1504-14.

19 Dex S, Joshi H. Children of the 21st century: from birth to nine months. Bristol: Policy, 2005.

20 Elliott C, Smith P, McCulloch K. British Ability Scales Second Edition (BAS II): administration and scoring manual. London: NFER-Nelson, 1996.

21 Hill V. Through the past darkly: a review of the British ability scales second edition. Child Adolesc Ment Health 2005;10:87-98.

22 Kessler RC, Andrews G, Colpe LJ, et al. Short screening scales to monitor population prevalences and trends in non-specific psychological distress. Psychol Med 2002;32:959-76.

23 Geiger A, Achermann P, Jenni OG. Association between sleep duration and intelligence scores in healthy children. Dev Psychol 2010;46:949-54.

24 Nixon GM, Thompson JM, Han DY, et al. Short sleep duration in middle childhood: risk factors and consequences. Sleep 2008;31:71-8.

25 El-Sheikh M, Buckhalt JA, Mize J, et al. Marital conflict and disruption of children's sleep. Child Dev 2006;77:31-43.

26 Kelly $Y$, Sacker A, Del Bono $E$, et al. What role for the home learning environment and parenting in reducing the socioeconomic gradient in child development? Findings from the Millennium Cohort Study. Arch Dis Child 2011;96:832-7.

27 Bates JE, Viken RJ, Alexander DB, et al. Sleep and adjustment in preschool children: sleep diary reports by mothers relate to behavior reports by teachers. Child Dev 2002;73:62-75.

28 McMunn A, Kelly Y, Cable N, et al. Maternal employment and child socio-emotional behaviour in the UK: longitudinal evidence from the UK Millennium Cohort Study. J Epidemiol Community Health 2012;66:e19.

29 Cummings EM, Davies PT. Effects of marital conflict on children: recent advances and emerging themes in process-oriented research. J Child Psychol Psychiatry 2002;43:31-63.

30 Werner $\mathrm{H}$, LeBourgeois MK, Geiger A, et al. Assessment of chronotype in four- to eleven-year-old children: reliability and validity of the Children's ChronoType Questionnaire (CCTQ). Chronobiol Int 2009;26:992-1014. 